Thorax, 1977, 32, 771-776

\title{
Carcinoid tumour of possible thymic origin: case report
}

\author{
UMA RAO ${ }^{1}$ AND HIROSHI TAKITA ${ }^{2}$ \\ From the Departments of Pathology ${ }^{1}$ and Thoracic Surgery ${ }^{2}$, Roswell Park Memorial Institute, Buffalo, \\ New York 14263, USA
}

Rao, U., and Takita, H. (1977). Thorax, 32, 771-776. Carcinoid tumour of possible thymic origin: case report. A case of carcinoid tumour of possible thymic origin in a 43-year-old man is presented. Carcinoid tumour arising in the anterior mediastinum (thymus) is a rare condition and only 26 cases have been reported in the past. A review of the literature showed that threequarters of the reported cases were asymptomatic but the remainder of patients presented with various endocrine symptoms.

Ultrastructurally the thymic carcinoid is similar to those found in other organs and also appears to be derived from Kultschitsky cells of the thymus gland.

Carcinoid tumours of the anterior mediastinum of thymic origin are rare. Such tumours are believed to arise from the Kultschitsky cells normally found in the thymus. They occur predominantly in the anterior and, rarely, posterior mediastinum. The median age is 43 years with male preponderance. They are indolent tumours and invasion of contiguous structures such as the lung and pericardium is common. Distant metastases have occurred in approximately one-half of reported cases. In a review of material from Roswell Park Memorial Institute between 1965 and 1976 only one case of carcinoid tumour of the anterior mediastinum was found.

\section{Case report}

A 48-year-old man had a chest radiograph which showed mediastinal widening not present one year earlier. He was completely asymptomatic. $\mathrm{He}$ was known to be hypertensive and was on spironolactone for this. Physical examination revealed only a blood pressure of $150 / 90 \mathrm{mmHg}$ and an ejection systolic murmur grade II/IV along the left sternal border, the rest of the examination being within normal limits. Tomography of the mediastinum revealed an anterior mediastinal mass involving the left hilar and paratracheal area extending to the upper manubrium sterni. There was no lesion in the lungs. Barium studies and fibreoptic bronchoscopy were normal. Bronchial washings contained no neoplastic cells. The mediastinum was explored by midline sternotomy incision in January 1976. A large, hard, nodular mass occupied the anterior mediastinum and invaded both pleurae and the anterior pericardium. The tumour was totally excised, along with portions of adherent pericardium and pleura. Lymph nodes in the neck and mediastinum were not macroscopically involved by tumour.

The excised tumour weighed $400 \mathrm{~g}$ and measured $11.5 \mathrm{~cm}$ in maximum diameter. It was encapsulated and nodular. Cut sections were grey, fleshy, and lobular with small scattered light yellow foci of necrosis measuring up to $2 \mathrm{~mm}$. Light microscopy revealed the tumour to be composed of round to oval cells with faintly granular pink cytoplasm and indistinct cell borders. Nuclei were uniform with an even chromatic pattern. Nucleoli were inconspicuous. Cells formed cohesive sheets and nests and occasionally formed short cords separated by fibrous septa and stroma. In addition, cells formed rosettes and were orientated towards a lumen (Fig. 1). No glycogen or argyrophilic granules were identified. Thymus gland was not identified. Sections from representative areas were processed for electron microscopy.

Electron microscopic studies showed tumour cells with relatively smooth cytoplasmic borders. Occasional desmosomes were present. Nuclei were round to oval and occasionally indented. The cytoplasm contained numerous globular mitochondria with well-preserved cristae (Fig. 2). Sparse profiles of rough endoplasmic reticulum were present. 


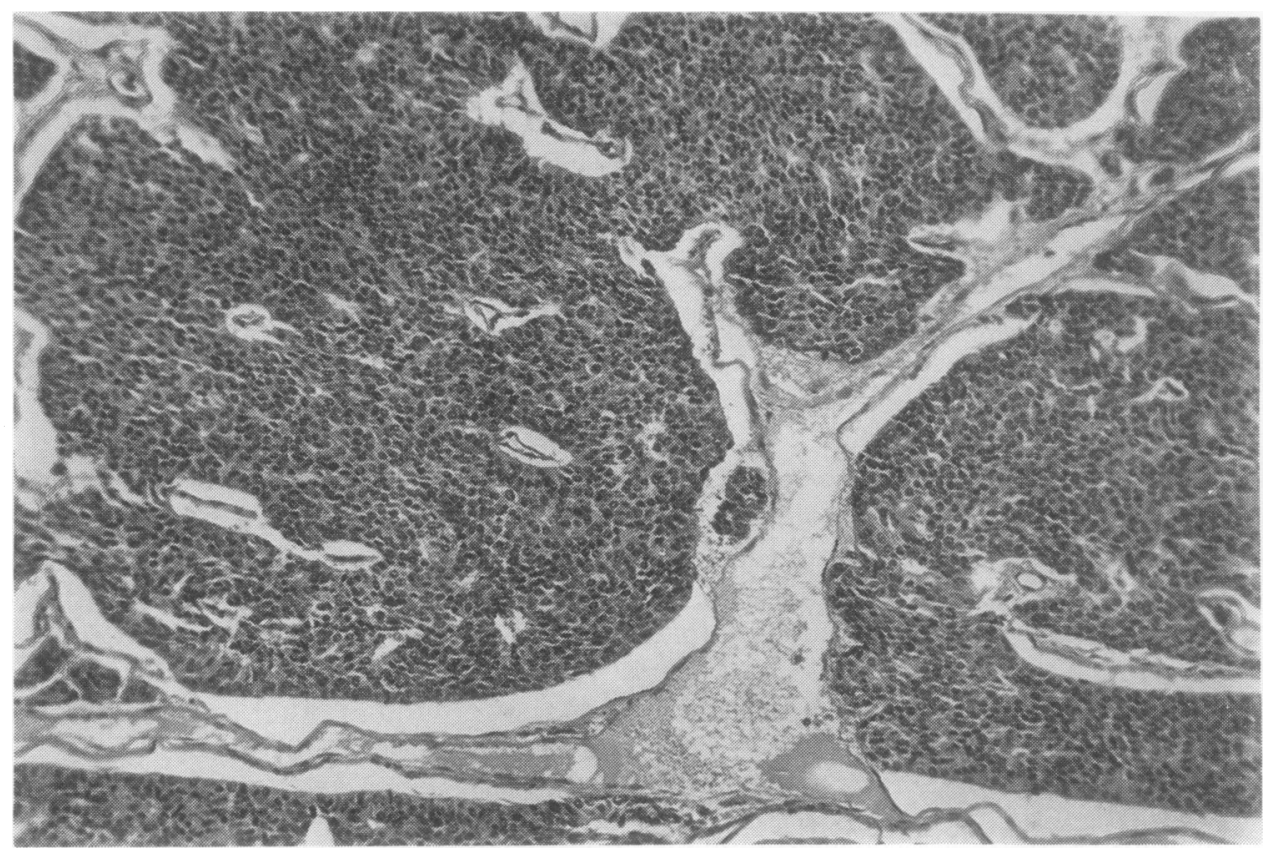

Fig. 1 Carcinoid tumour of mediastinum. Note uniformity of cells and occasional rosette formation (Haematoxylin and eosin $\times 200$ ).

Golgi apparatus was well developed. The most striking feature was the presence of numerous membrane-bound granules with little variation in electron density. The size varied from 90 to 150 $\mathrm{m} \mu$. The larger granules were more electron dense and had closely approximated membrane, while the smaller ones were less dense and separated from their membranes by a halo (Fig. 2). Foci indicating their origin from the Golgi apparatus were not found on examination of several blocks of tissue. The granules were scattered throughout the cytoplasm of the cells, but occasionally they tended to be concentrated within pseudopod-like processes, which were interposed between two cells. Some cells, in addition, showed microvillous projections, some being bounded by desmosomes, and were orientated towards a lumen. Glycogen and tonofilaments were not found. Basement membrane was absent. Light and dark cells were observed in sections although this feature appeared to be related to the state of preservation of the cell rather than the character of the hyaloplasm.

His postoperative course was uneventful and he was given radiation therapy (5000 rads in a period of five weeks). Since then the patient has been doing well with no evidence of recurrence up to November 1976.

\section{Discussion}

Carcinoid tumour includes a family of closely related neoplasms which probably have a common progenitor cell. These tumours commonly occur in the gastrointestinal tract, bronchi, and, rarely, the ovary and testis. Regardless of their location they are histochemically and pathologically similar. Two other closely related tumours of foregut $\frac{O}{3}$ origin which have morphological and behavioural characteristics similar to carcinoids are medullary $\frac{9}{5}$ carcinoma of the thyroid and islet-cell carcinoma $\frac{D}{O}$ of the pancreas (Pearse, 1969).

Carcinoids of possible thymic origin are rare, $N$ only 26 cases being reported in the literature. The median age was 43 years with a male preponder- $N$ ance. Average survival after complete surgical $\omega$ excision was five and a half years, one patient living as long as 12 years. These tumours presum- $\bullet$ ably arise from the enterochromaffin cells present $\stackrel{\Phi}{\Phi}$ in the thymus which is a derivative of the second? and third bronchial pouches. These cells were $\frac{T}{0}$ demonstrated in the thymus by electron micro- $\frac{\vec{D}}{\mathbb{D}}$ scopy by Rosai and Higa (1972), who found $\stackrel{?}{\mathbb{D}}$ argyrophilic cells in four of 20 human thymuses $\varrho$ and in chicken thymuses. Three-quarters of the reported cases were not associated with any endo- 8 




Fig. 2(a) Electron micrograph of carcinoid tumour showing cells with fairly smooth cell borders, rare desmosome, and well-developed Golgi apparatus $(\times 15400)$. 


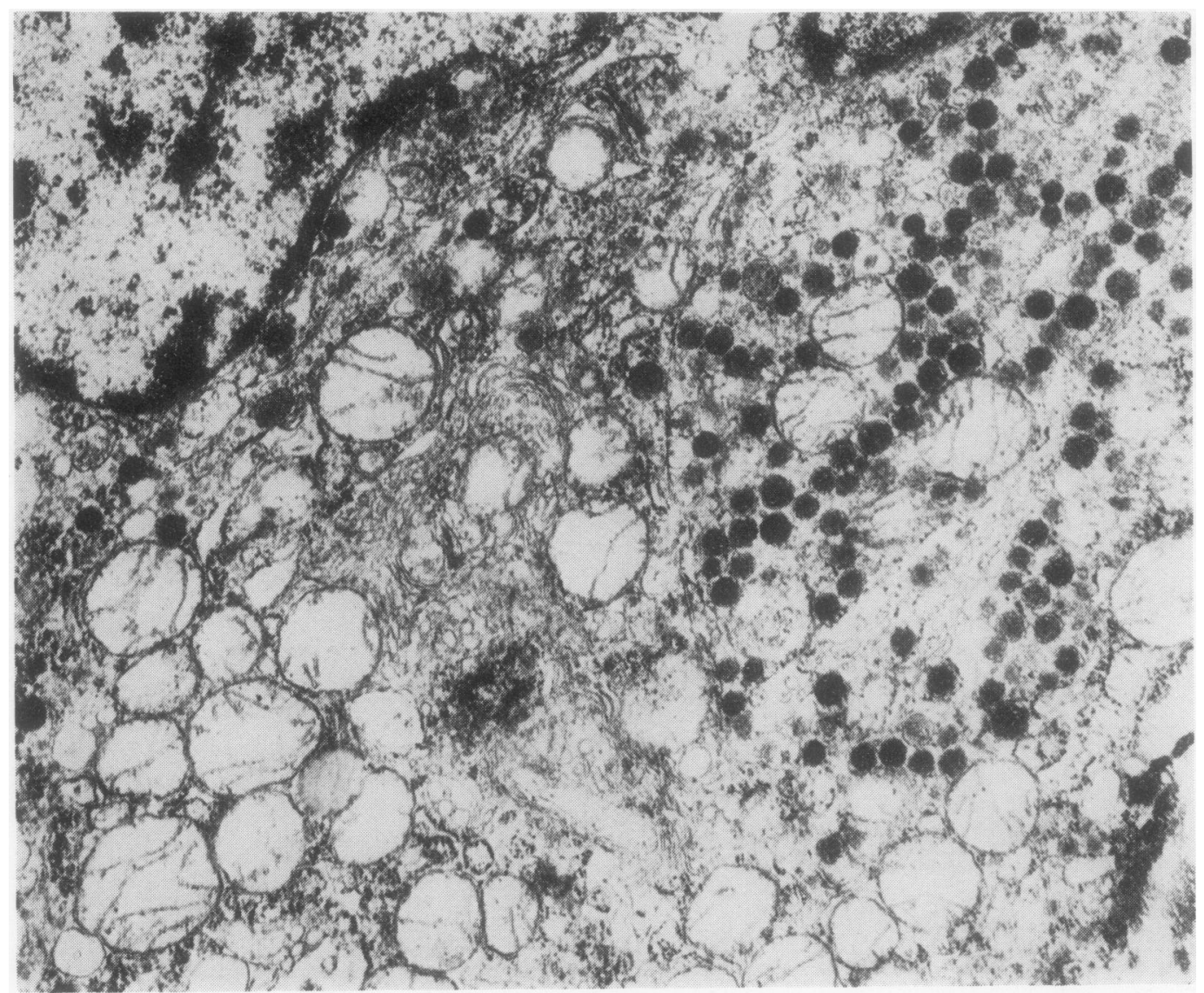

Fig. 2(b) Higher magnification showing characteristic membrane-bound secretory granules which show little variation in electron density and size $(\times 35000)$. 


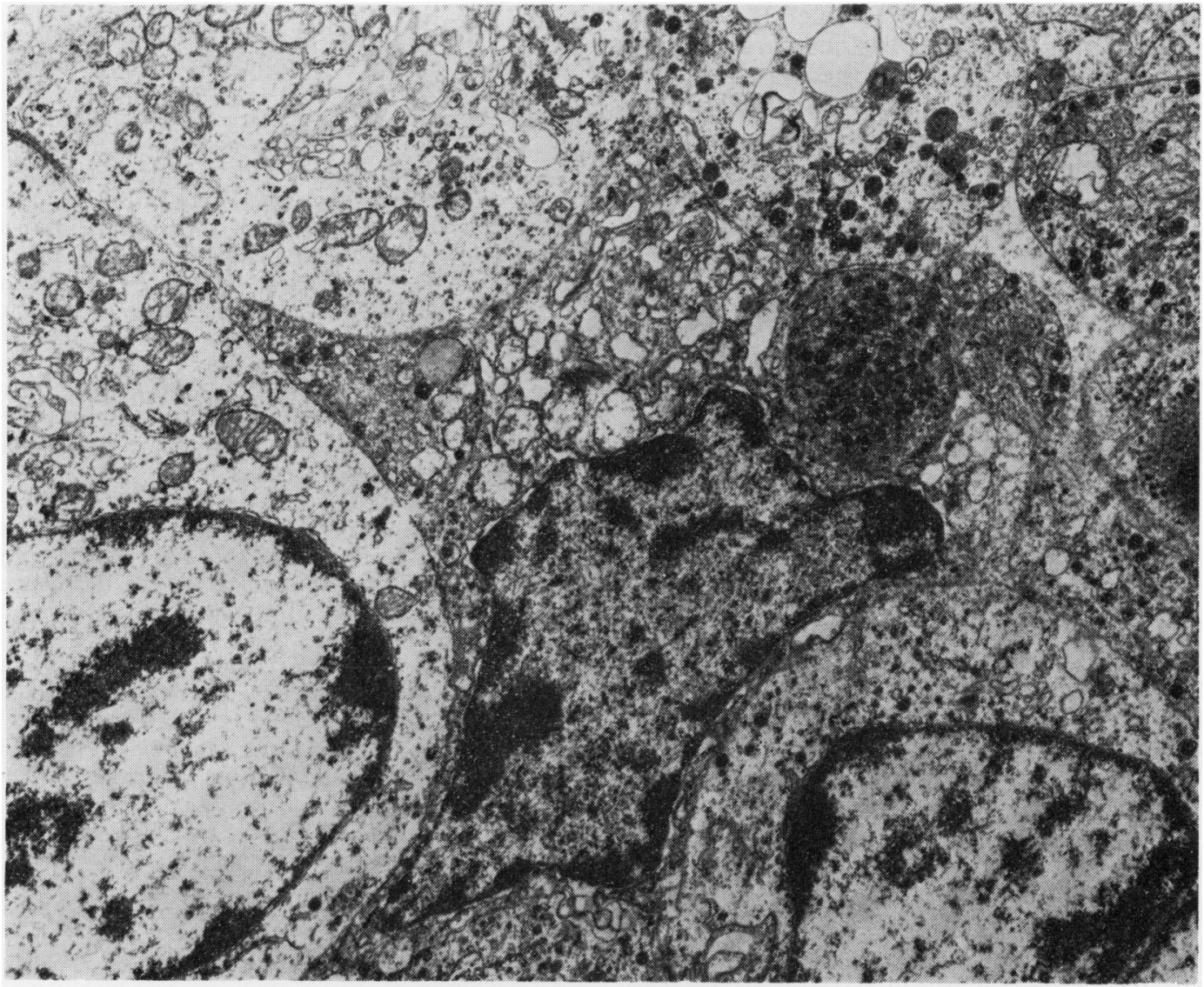

Fig. 2(c) Secretory granules in cell body and cytoplasmic processes interposed between cells. Note that the lighter cells appear to be better preserved than the 'dark' cell at the centre $(\times 15000)$. 
crine symptoms. Three cases had evidence of ectopic ACTH production (Lemon et al., 1966; Kay and Willson, 1970; Tanaka, 1976). One case had systemic symptoms including polyarthropathy and clubbing (Lowenthal et al., 1974) associated with mediastinal carcinoid-like tumour which showed typical neurosecretory granules by electron microscopy. Three cases of Rosai et al. (1971) had associated multiple endocrine adenomatosis. However, the presence of neurosecretory granules within cells does not correlate with the presence of endocrine symptoms. Rosai and Higa (1972) reported eight cases of mediastinal carcinoid and reviewed seven previously reported cases. Hughes et al. (1975) and Salyer et al. (1976) reported four cases without evidence of endocrine disease.

Our case is similar to the above case reports with respect to its location in the anterior superior mediastinum and its histological characteristics. In addition, our patient had no evidence of tumour in either the bronchi, lungs, or gastrointestinal tract, and we presume, therefore, that the carcinoid tumour is primary in the mediastinum and probably is of thymic origin. In the previously reported cases only five showed normal thymic tissue adjacent to the tumour.

Ultrastructurally, the thymic carcinoid is similar to those found in other organs. These thymic lesions differ from the other epithelial thymomas by the absence of tonofilaments, glycogen, desmosome-connected lysosomes, or basal lamina. Neurosecretory granules have not been described in epithelial thymomas (Kay, 1970; Levine and Bensch, 1970; Levine et al., 1975). No relationship of tumour cell to lymphocytes or blood vessel was observed in this case. This type of mediastinal tumour also differs from the conventional thymoma clinically in that it is not reported to be associated with myasthenia gravis or red cell hypoplasia. Carcinoids of the thymus are identical with bronchial carcinoids described in the literature, which are also derived from bronchial Kultschitsky cells (Bensch et al., 1965; Gmelich, et al., 1967; Hage, 1973). We compared the ultrastructural features of the mediastinal carcinoid to the bronchial carcinoid and found them to be identical, and it is possible that the former arise from Kultschitsky cell rests present within the thymus.

\section{References}

Bensch, K. G., Gordon, G. B., and Miller, L. R. (1965). Electron microscopic and biochemical studies on the bronchial carcinoid tumor. Cancer, 18, 592-602.
Gmelich, J. T., Bensch, K. G., and Liebow, A. A. 므 (1967). Cells of Kultschitsky type in bronchioles 흘 and their relation to the origin of peripheral car- $\frac{\bar{\omega}}{\partial}$

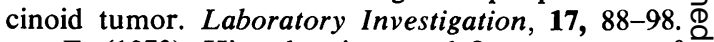

Hage, E. (1973). Histochemistry and fine structure of bronchial carcinoid tumors. Virchows Archiv Abt. ${ }^{\text {क }}$ A Pathologische Anatomie, 361, 121-128.

Hughes, J. P., Ancalmo, N., Leonard, G. L., and Ochsner, J. L. (1975). Carcinoid tumor of thymus $\vec{\omega}$ gland. Report of a case. Thorax, 30, 470-475.

Kay, S. (1970). Comparative ultrastructural studies on $\vec{x}$ three thymic lesions. Archives of Pathology, 90, $416-422$.

Kay, S., and Willson, M. A. (1970). Ultrastructural studies of an ACTH secreting thymic tumor. Cancer, $\underset{ }{\perp}$ 26, 445-452.

Lemon, F. C., Fine, M. B., Grasso, S. G., and Kinsell, $\stackrel{\circ}{\rightarrow}$ L. W. (1966). ACTH-like activity in a thymoma associated with gonadal dysegenesis. Journal of $\mathbb{D}$ Clinical Endocrinology and Metabolism, 26, 1-5.

Levine, G. D., and Bensch, K. G. (1970). Epithelial $\frac{\partial}{\sigma}$ nature of spindle-cell thymoma. Cancer, 30, 500-511. Ф

Levine, G. D., Rosai, J., Bearman, R. M., and $\overrightarrow{1}$ Polliack, A. (1975). The fine structure of thymoma, $\underset{V}{ }$ with emphasis on its differential diagnosis. American. Journal of Pathology, 81, 49-65.

Lowenthal, R. M., Gumpel, J. M., Kreel, L., Mc- O Laughlin, J. E., and Skeggs, D. B. L. (1974). Carcinoid tumour of the thymus with systemic manifestations: Thorax, 29, 553-558.

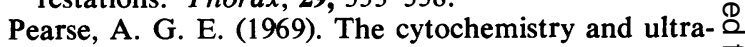
structure of polypeptide hormone-producing cells $\overrightarrow{\vec{\sigma}}$ of the APUD series and the embryologic, physi- 3 ologic and pathologic implications of the concept. $\vec{P}$ Journal of Histochemistry and Cytochemistry, 17, 303-313.

Rosai, J., and Higa, E. (1972). Mediastinal endocrine neoplasm of probable thymic origin, related to carcinoid tumor. Cancer, 29, 1061-1074.

Rosai, J., Higa, E., and Davie, J. (1971). Mediastinal $\frac{0}{3}$ endocrine neoplasm in patients with multiple endocrine adenomatosis. Cancer, 29, 1075-1083.

Salyer, W. R., Salyer, D. C., and Eggleston, J. C. (1976). Carcinoid tumors of the thymus. Cancer, 137, 윽

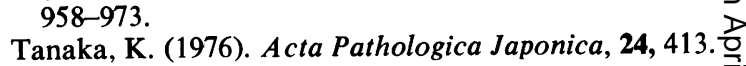

Requests for reprints to: Dr. Uma Rao, Roswell Park Memorial Institute, 666 Elm Street, Buffalo, New York 14263, USA. 